\title{
Effect of co-deposited SiC nanowires and carbon nanotubes on oxidation resistance for $\mathrm{SiC}$-coated $\mathrm{C} / \mathrm{C}$ composites
}

Caixia Huo, Lingjun Guo*, Yunyu Li, Changcong Wang, Lei Feng, Ningkun Liu, Yulei Zhang, Kaiyuan Dong, Qiang Song

\begin{abstract}
To protect carbon/carbon composites $(\mathrm{C} / \mathrm{Cs})$ against oxidation, $\mathrm{SiC}$ coating toughened by $\mathrm{SiC}$ nanowires (SiCNWs) and carbon nanotubes (CNTs) hybrid nano-reinforcements was prepared on $\mathrm{C} / \mathrm{Cs}$ by a two-step technique involving electrophoretic co-deposition and reactive melt infiltration. Co-deposited SiCNWs and CNTs with different shapes including straight-line, fusiform, curved and bamboo dispersed uniformly on the surface of $\mathrm{C} / \mathrm{Cs}$ forming three-dimensional networks, which efficiently refined the $\mathrm{SiC}$ grains and meanwhile suppressed the cracking deflection of the coating during the fabrication process. The presence of SiCNWs and CNTs contributed to the formation of continuous glass layer during oxidation, while toughed the coating by introducing toughing methods such as bridging effect, crack deflection and nanowire pull out. Results showed that after oxidation for $45 \mathrm{~h}$ at 1773 $\mathrm{K}$, the weight loss percentage of $\mathrm{SiC}$ coated specimen was $1.35 \%$, while the weight gain percentage of the $\mathrm{SiCNW}$ /CNTs reinforced $\mathrm{SiC}$ coating was $0.03052 \%$ due to
\end{abstract}


the formation of continuous glass layer. After being exposed for $100 \mathrm{~h}$, the weight loss percentage of the SiCNWs/CNTs reinforced $\mathrm{SiC}$ coating was $1.08 \%$, which is relatively low.

Keywords: Co-deposition; Carbon nanotubes; $\mathrm{SiC}$ nanowires; Carbon/carbon composites; $\mathrm{SiC}$ coating; Oxidation resistance

\section{Introduction}

Owing to excellent properties at high temperatures, such as high strength-to-weight ratio and good thermal shock resistance, carbon/carbon composites $(\mathrm{C} / \mathrm{Cs})$ are considered as a leading candidate for high temperature application in aeronautical and aerospace field [1-3]. However, C/Cs showed significant oxidation degradation under oxidizing environment above $773 \mathrm{~K}$, which limited their application in oxygen-containing environment [4-6]. Numerous studies showed that the anti-oxidation property of $\mathrm{C} / \mathrm{Cs}$ could be improved by preparing an oxidation-resistant coating [7-8]. So far, various coating systems, especially the silicide coatings have been fabricated on the surface of $\mathrm{C} / \mathrm{Cs}$ to enhance its isothermal oxidation resistance [9-11]. Among these coatings, $\mathrm{SiC}$ ceramic is regarded as one of the most promising materials for protect $\mathrm{C} / \mathrm{Cs}$ at high temperature due to its excellent anti-oxidation property and good compatibility with C/Cs [8] [12][13].

In spite of the outstanding properties of $\mathrm{SiC}$ coating, while its application in oxidizing atmosphere is limited because of the mismatch of coefficient of theraml expansion (CTE) between $\mathrm{SiC}$ coating $\left(\alpha=5 \times 10^{-6} / \mathrm{K}\right)$ and $\mathrm{C} / \mathrm{Cs}\left(\alpha=1 \times 10^{-6} / \mathrm{K}\right)$, which will induce the cracks in the coating under service during rapid cooling-down 
process, and lead to the failure of the coating eventually [7]. Many methods have been employed to solve this issue [14], such as introducing carbon nanotubes (CNTs) [15], $\mathrm{SiC}$ nanoparticles [16], SiC whiskers [17-18] and $\mathrm{SiC}$ nanowires (SiCNWs) [19-24] into the SiC coating. The introduction of these reinforcement phases aimed to improve the toughness of the coating and reduce the size of cracks. CNTs are more suitable for reinforcing the coating than whiskers and nanoparticles due to the CNTs exhibit high mechanical strength, high electronic and thermal conductivity [25-26]. Nevertheless, SiC coating toughed by SiCNWs and CNTs hybrid reinforcement has not yet been thoroughly investigated. To date, there are limited papers comparing the microstructures and characteristics of the $\mathrm{SiC}$ coatings prepared by reactive melt infiltration with and without SiCNWs and CNTs hybrid reinforcement, which might be ponderable for practical applications.

In this work, SiCNWs and CNTs hybrid reinforcement toughed SiC coating were prepared on C/Cs by a two-step technique involving electrophoretic deposition (EPD) and reactive melt infiltration (RMI) (as shown in Fig. 1). Firstly, SiCNWs and CNTs were deposited on C/Cs using EPD to increase the oxidation resistance for SiC-coated C/Cs. Secondly, the treated specimens were coated with $\mathrm{SiC}$ via the reactive melt infiltration technique. The effect of the co-deposition of SiCNWs and CNTs on the microstructure and oxidation behavior of the SiC coating was analyzed.

\section{Experiment}

$\mathrm{C} / \mathrm{C}$ specimens $(10 \mathrm{~mm} \times 10 \mathrm{~mm} \times 10 \mathrm{~mm})$ were used as substrates for coating, which were cut from bulk 2D C/Cs with a density of $1.71 \mathrm{~g} / \mathrm{cm}^{3}$. The preparation of 
the 2D C/Cs was as follows: Carbon felts $\left(0.4 \mathrm{~g} / \mathrm{cm}^{3}\right.$, Yixing Tianniao High Technology Co., Ltd., Jiangsu, China) were fabricated by alternatively stacked carbon fiber webs and non-woven layers by a needle-punching technique, which were chosen as the porous preform materials. The fabrics were deposited by pyrolytic carbon (PyC) through thermal gradient chemical vapor infiltration (TCVI) process. During TCVI process, methane gas $\left(\mathrm{CH}_{4}\right)$ was used as carbon source and nitrogen $\left(\mathrm{N}_{2}\right)$ was used as carrier gas. The deposition temperature was $1000^{\circ} \mathrm{C}-1300^{\circ} \mathrm{C}$. After $100-200 \mathrm{~h}$, the density of the porous preforms was about $1.70-1.75 \mathrm{~g} / \mathrm{cm}^{3}$. After being hand-abraded using 300 grit SiC paper and ultrasonically cleaned with ethanol, they were dried at $80{ }^{\circ} \mathrm{C}$ for $24 \mathrm{~h}$. C/C specimens were divided into two groups, one of which was co-deposited SiCNWs and CNTs film through EPD. The other group was pure C/Cs without any treatment for comparison. SiCNWs (92\% purity) were provided by Zhuo Xi High-tech (Xi'an, China). An aqueous suspension of commercially available multi-walled CNTs (97\% purity) were provided by Timesnano (Chengdu, China).

EPD is a mild method with low energy consumption and outstanding ability to homogeneously coat complex shapes with easily controlled film thickness and density [27-29]. A schematic of the EPD process is illustrated in Fig. 2. The detailed process for EPD was conducted as follows: firstly, the CNT aqueous suspensions were diluted with isopropanol by volume ratio of $1: 10$, and $\mathrm{SiCNW}$ s were added into the mixed solution by weight ratio of 1:1500. They were dispersed with isopropanol and then homogenized in ultrasonic bath for $4 \mathrm{~h}$. Secondly, a stainless steel cylinder with the diameter of $50 \mathrm{~mm}$ was vertically placed on an EPD cell containing SiCNWs and 
CNTs suspension, which was used as anode. The cathode, a C/C specimen connected with a copper wire, was fixed in a plastic frame. And then, $\mathrm{C} / \mathrm{C}$ specimen was immersed in the center of the stainless steel cylinder. The experiment was conducted using an electrophoresis apparatus (PowerPac Basic, Bio-Rad Laboratories, Inc., USA), which was performed at a constant voltage of $60 \mathrm{~V}$. The time of EPD was $120 \mathrm{~s}$. The thickness of the co-deposited SiCNWs and CNTs film can be adjusted by controlling the voltage and EPD time [14].

Finally, pure C/Cs and EPD treated C/Cs were both coated with SiC ceramic coating using the same reactive melt infiltration technique. Powder compositions for the reactive melt infiltration process were as follows: 60-80 wt.\% Si (Jiuling Smelting Co., Ltd., Shanghai, China), 10-25 wt.\% graphite (Carbon Plant, Xi' an, China) and 5-15 wt.\% $\mathrm{Al}_{2} \mathrm{O}_{3}$ (Guoyao Chemical Reagent Co., Ltd., Shanghai, China). All the above powders were analytical grade with the granularity of 300 mesh. Then the powder mixtures were blending for $3 \mathrm{~h}$ using a blender. The specimens and the powder mixtures were placed in a graphite crucible with a graphite lid, and then heated in an argon atmosphere to $1873-2273 \mathrm{~K}$ and held at that temperature for $2 \mathrm{~h}$ by an electric furnace with the pressure of $3 \mathrm{kPa}$. After the coating deposition, the furnace cooled down to room temperature naturally. The specimens were removed from the graphite crucible and ultrasonically cleaned to remove impurity.

Isothermal oxidation test of the $\mathrm{SiC}$ coated samples were carried out at $1773 \mathrm{~K}$ in static air in a furnace to evaluate the anti-oxidation ability of the coating. The specimens were taken out from the furnace and cooled down naturally. The mass of 
the coated $\mathrm{C} / \mathrm{C}$ specimens was measured by an electronic precision balance with a sensitivity of $\pm 0.1 \mathrm{mg}$. Subsequently, they were put into the furnace again for the next cycle. Weight change percentages of the specimens were calculated by the following equation $[30-31]$ :

$$
\mathrm{W} \%=\frac{\mathrm{m}_{0}-\mathrm{m}_{1}}{\mathrm{~m}_{0}} \times 100 \%
$$

Where $m_{0}$ and $m_{1}$ represent the initial and final mass of the specimens for each cycle during isothermal oxidation process.

Raman (Raman, RENISHAW invia Raman Microscope) characterization was used to study the graphitic structure evolution of the co-deposition of SiCNWs and CNTs film and $\mathrm{C} / \mathrm{C}$ specimens. The crystalline structures of the SiCNWs/CNTs-reinforced SiC coating was analyzed by X-ray diffraction (XRD, PANalytical X' Pert Pro, Netherlands) with $\mathrm{Cu} K \alpha(\lambda=0.1542 \mathrm{~nm}), 0.03^{\circ}$ step size and $0.28 \%$ s scan speed radiation. Field emission scanning electron microscope (SEM, ZEISS Supra 55) and transmission electron microscopy (TEM, FEI Tecnai F30 G2) were used to identify the morphology and structures of the specimens.

\section{Results and discussion}

\subsection{Morphology of SiCNWs and CNTs film}

For the co-deposition of SiCNWs and CNTs film, the value of $\mathrm{I}_{\mathrm{D}} / \mathrm{I}_{\mathrm{G}}$ suggests a significantly change. In Fig. 3, there are four main bands in Raman spectra of the co-deposited SiCNWs and CNTs film (curve (a)). The two bands located at $\sim 789 \mathrm{~cm}^{-1}$ and $\sim 966 \mathrm{~cm}^{-1}$ are the characteristic peak of SiC [32]. The disorder-induced D band $\left(\sim 1348 \mathrm{~cm}^{-1}\right)$ and the tangential $\mathrm{G}$ band $\left(\sim 1575 \mathrm{~cm}^{-1}\right)$ were the characteristic peak of 
CNTs [30]. From curve (a) in Fig. 3, SiCNWs and CNTs film has been successfully co-deposited on C/Cs. The substrate covered with CNTs and SiCNWs film has an $\mathrm{I}_{\mathrm{D}} / \mathrm{I}_{\mathrm{G}}$ of 0.504 , which indicates a significantly decrease in the graphization degree of $\mathrm{C} / \mathrm{Cs}$ (curve (b), 0.789). This decreased value of the $\mathrm{I}_{\mathrm{D}} / \mathrm{I}_{\mathrm{G}}$ suggests a significantly change on the $\mathrm{C} / \mathrm{Cs}$ surface after the co-deposition.

The deposited SiCNWs and CNTs film (shown in Fig. 4(a)) shows a dense structure with the thickness around $20 \pm 2 \mu \mathrm{m}$ and they are randomly oriented and bridged with each other (seen in Fig. 4(b)). An enlarged image shown in Fig. 4(c) reveals the formation of SiCNWs were with various shapes including straight-line shape, fusiform shape and bamboo shape. Among that the bamboo shaped SiCNW consists of some nodes and a thinner stem. In addition, various shapes of CNTs with straight and curly can be detected. Plenty of pores generated within the SiCNWs and CNTs structure, which is beneficial to the flowing of $\mathrm{Si}$ during reactive melt infiltration technique.

As shown in the Fig. 5(a)-(c), the as deposited SiCNWs have a diameter in the range of $100-500 \mathrm{~nm}, \mathrm{CNTs}$ have a diameter in the range of $10-100 \mathrm{~nm}$, and both of them were over ten micrometers in their lengths, measured from more than eighty SiCNWs and CNTs using Digital Micrograph software. It also can be observed that the surface morphology of SiCNWs is rugged, and CNTs distributed in the structure provided by the SiCNWs.

\subsection{Phase composition and microstructure evolution of as-deposited SiC coating}

The surface of the two kinds of specimens show a significantly difference after being coated with $\mathrm{SiC}$ grains. Fig. 6 shows the micro-structure of the SiC coating 
without (Fig. 6(a)) and with (Fig. 6(b)) SiCNWs and CNTs film. The shape and dimension of $\mathrm{SiC}$ crystals are significantly changed, the $\mathrm{SiC}$ crystals grown without SiCNWs and CNTs is in a hexagonal shape with the size about $60-100 \mu \mathrm{m}$. In contrast, the $\mathrm{SiC}$ crystals of the $\mathrm{SiCNW}$ and CNTs modified SiC coating are spherical with a dimension about $6-10 \mu \mathrm{m}$, which is significantly smaller. Moreover, these spherical particles interconnect with each other forming a dense structure. The difference is mainly attributed to the introduction of the SiCNWs and CNTs film. The grown process of the SiCNWs and CNTs modified SiC coating is heterogeneous nucleation. Plenty of nucleation points provided by the as-deposited SiCNWs and CNTs are beneficial to the growth of SiC grains to form coating on the surface of SiCNWs and CNTs. The grown process needs lower $\Delta \mathrm{T}$ (degree of under cooling) and $\triangle G$ ( Gibbs free energy) than that of SiC coating without the SiCNWs and CNTs film. So the less nucleation points can be supplied for the growth of the SiC grains without SiCNW s and CNTs, which is unfavorable for SiC crystal nucleation. And the nucleation of $\mathrm{SiC}$ crystal is suppressed due to release a great deal of heat energy during the growth of $\mathrm{SiC}$ grains.

In addition, some micro-cracks can be seen in Fig. 6(a), which will lead to the thermal stress concentration during oxidation. Once coming to a certain degree, the thermal stress (concentrated at the tip of the micro-cracks) will force the micro-cracks to expand, and finally form penetrative cracks within the coating. On the contrary, no obvious cracks appeared in the SiCNWs and CNTs film modified SiC coating showing in Fig. 6(b). The insert graph in Fig. 6(b) is the partial magnification of the 
SiCNWs and CNTs film modified SiC coating. Since the rough surface of SiCNWs and CNTs can provide more interfaces than that of the smooth surface with the same length, it could generate lots of interfaces and nuclei for SiC nucleation. Therefore, the uniformly distributed of nucleation is conductive to increase the compactness of $\mathrm{SiC}$ coating. Meanwhile, the rugged surface of SiCNWs and the structure formed by CNTs and SiCNWs will improve the mechanical property[13, 19] by enhancing bonding strength of the coating and $\mathrm{C} / \mathrm{Cs}$, therefore, it needs more energy when pulling SiCNWs out of the SiC coating.

SiCNWs and CNTs were used as reinforcing phases, which could play an important role in avoiding the cracking generation and deflection of the coating caused by the mismatch of CTE between the substrates and the coating.

The XRD pattern of SiC coating reinforced by SiCNWs and CNTs is shown in Fig. 6(c). It can be observed that the coating was composed of $\alpha$-SiC, $\beta-\mathrm{SiC}$ and $\mathrm{Si}$ phases. Moreover, the intensity of the $\mathrm{SiC}$ diffraction peaks is very strong, which suggests a good crystallization of the $\mathrm{SiC}$ grains. The generation of $\mathrm{SiC}$ phase is derived from the chemical reaction between $\mathrm{C}$ and $\mathrm{Si}$. In addition, Si diffraction peaks can also be found, which is caused by the excess Si powders in original pack materials. The XRD pattern shows that $\mathrm{SiC}$ ceramic was successfully formed by reactive melt infiltration technique and has a good crystallization of the SiC grains.

Fig. 6(d) and Fig. 6(e) are the high magnification SEM images of SiCNWs and CNTs existed within SiC coating, separately. The continuous glass layer generated on the SiC surface owe to the reinforcement by SiCNWs and CNTs, which indicates that 
SiCNWs and CNTs can modify the coating and reduce the quantity and size of the micro-cracks in certain level. The CNTs (Fig. 6(e)) were surrounded by SiC coating, which exhibit a strong and coherent interface bonding with SiC coating. The curly shape of CNTs can provide a better capability to release thermal stress during isothermal oxidation process, which is helpful to reduce the size of the micro-cracks and form a continuous coating.

Simultaneously, the fracture morphology of the $\mathrm{SiC}$ coating on $\mathrm{C} / \mathrm{Cs}$ toughed by SiCNWs and CNTs were observed in Fig. 6. Numerous SiCNWs and CNTs connect with the grain can be clearly detected, as shown in Fig. 6f, which contribute to improve the toughness of the coating and restrain the crack to extend. When the SiCNWs and CNTs are pinned into the adjoining coating (Fig. 6(e) and (f)), the stress will be effectively transferred to the SiCNWs and CNTs. The load will be borne by the SiCNWs and CNTs due to their excellent mechanical properties and result in an increase in elastic modulus and the hardness of the coating [14].

\subsection{Oxidation mechanism}

The oxidation protective ability of the coating with and without SiCNWs and CNTs film were investigated at a temperature of $1773 \mathrm{~K}$ in air. The weight loss percentage curves of the two kinds of specimens during oxidation were shown in Fig. 7.

From Fig. 7, the weight loss percentage of the $\mathrm{SiC}$ coated $\mathrm{C} / \mathrm{C}$ specimen without SiCNWs and CNTs film was $1.35 \%$ after isothermal oxidation at $1773 \mathrm{~K}$ for $45 \mathrm{~h}$. While toughened by the co-deposition of SiCNWs and CNTs film, coated specimen 
gains its weight in the beginning $45 \mathrm{~h}$ and then comes to lose weight. As the oxidation time reaches up to $45 \mathrm{~h}$, the weight gain percentage was $0.03052 \%$. After being exposed for $100 \mathrm{~h}$, the weight loss percentage of the specimen was only $1.08 \%$. This result indicated that the $\mathrm{SiC}$ coated $\mathrm{C} / \mathrm{C}$ specimen without $\mathrm{SiCNW}$ and CNTs film exhibited a poor oxidation protective ability. After incorporating the SiCNWs and CNTs into the coating, the weight loss percentage of $\mathrm{C} / \mathrm{C}$ composites has been significantly decreased.

During the oxidation process of the coated specimens at $1773 \mathrm{~K}$, the phenomenon of the weight change can be explained by the following equations [34-36]:

$$
\begin{aligned}
& \mathrm{SiC}(\mathrm{s})+2 \mathrm{O}_{2}(\mathrm{~g}) \rightarrow \mathrm{CO}_{2}(\mathrm{~g})+\mathrm{SiO}_{2}(\mathrm{l}) \\
& 2 \mathrm{SiC}(\mathrm{s})+3 \mathrm{O}_{2}(\mathrm{~g}) \rightarrow 2 \mathrm{CO}(\mathrm{g})+2 \mathrm{SiO}_{2}(\mathrm{l}) \\
& \mathrm{Si}(\mathrm{s})+\mathrm{O}_{2}(\mathrm{~g}) \rightarrow \mathrm{SiO}_{2}(\mathrm{l}) \\
& 2 \mathrm{C}(\mathrm{s})+\mathrm{O}_{2}(\mathrm{~g}) \rightarrow 2 \mathrm{CO}(\mathrm{g}) \\
& \mathrm{C}(\mathrm{s})+\mathrm{O}_{2}(\mathrm{~g}) \rightarrow \mathrm{CO}_{2}(\mathrm{~g})
\end{aligned}
$$

According to the equations (2)-(4), the weight-increasing phenomenon of the coated specimen reinforced with SiCNWs and CNTs could be expounded clearly. While the oxidation of $\mathrm{C} / \mathrm{C}$ composites with weight-decreasing processes might be interpreted by the equations (5) and (6). Thus the weight gain process of the coated specimens during oxidation is mainly induced by the oxidation of the SiC coating, while the weight loss process of the coated specimens is mainly caused by the oxidation of the $\mathrm{C} / \mathrm{C}$ substrate and the volatility of oxidation production. Whether the 
specimen gain or lose weight concerns two factors: the oxidation dynamics of the coating and the compactness of the coating.

A phenomenon of particular interest is the slope of the weight loss curve changes with the increase of oxidation time after introducing SiCNWs and CNTs. Firstly, the curve decreases from $0 \mathrm{~h}$ to $15 \mathrm{~h}$, and turns almost flat from $15 \mathrm{~h}$ to $25 \mathrm{~h}$, after $25 \mathrm{~h}$ the curve shows an increase, then turns flat again after $70 \mathrm{~h}$. The slope changes of the curve indicate different oxidation mechanisms control the oxidation behavior of the coated $\mathrm{C} / \mathrm{C}$ specimens. The weight gain process indicates that the dense structure of the SiC coating, which was formed by the introduction of the co-deposition of SiCNWs and CNTs by EPD. This dense structure can protect the specimen from oxidation. With the increase of oxidation time, the weight loss process of the coated specimens is mainly caused by the oxidation of the $\mathrm{C} / \mathrm{C}$ substrate and the volatilization of oxidation production. The schematic illustration of the isothermal oxidation process of the coating is presented in Fig. 8.

As the SiC-coated specimens were oxidized at high temperature (Fig. 8 (a)), SiC coating was enclosed by oxygen. The continuous melting $\mathrm{SiO}_{2}$ glass layer was formed at the top of coating (Fig. 8 (b)), which contributes to the crack-healing and reduce the formation of the gap at the beginning of oxidation. As the extensive of the oxidation time, the depletion of $\mathrm{SiC}$ coating can induce the formation of the gap. This depletion is occurred by the oxidation and sublimation. The former results in the formation of $\mathrm{CO}_{2}(\mathrm{~g})$ and $\mathrm{CO}(\mathrm{g})$ (equation (2) and (3)), while the latter leads to the formation of the protective $\mathrm{SiO}_{2}$ (equation (2), (3) and (4)) glass layer. Once the oxidation products 
including liquid glass phase are difficult to seal cracks (Fig. 8(c)), oxygen can penetrate into the coating, and lead to the degradation of C/C composites (Fig. 8(d)).

As for the SiCNWs/CNTs-toughened SiC coating, oxygen can contact with coating to react directly (Fig. 8e). The oxidation of $\mathrm{SiC}$ and $\mathrm{Si}$ occurs when being exposed to the air at the beginning of oxidation (equation (2) and (3)), the oxidation rate of which is faster than the self-healing stage. This process is controlled by the oxidation of $\mathrm{SiC}$ and $\mathrm{Si}$, and the oxidation products result in the weight gain. With the oxidation time increased, the existence of SiCNWs and CNTs, which is composed by various shapes, sizes and properties, contributes to the formation of a protective and continuous $\mathrm{SiO}_{2}$ glass layer on the surface of the coating (Fig. 8(f)). The generated glass layer own well fluidity and low oxygen diffusion at elevated temperatures, which conduces to restrict the cracks growth within the coating and prevents oxygen from diffusing to $\mathrm{C} / \mathrm{C}$ composites. The oxidation process is controlled by the oxidation diffusion. Nevertheless, few micro-cracks still form in the coating during cooling period (Fig. 8(g)), which provide the channel for oxygen diffusion to the interface between coating and the $\mathrm{C} / \mathrm{C}$ substrate. Therefore, carbon would react with oxygen, and release $\mathrm{CO}$ and $\mathrm{CO}_{2}$ gasses (Fig. 8(h) and (i)). This moment the coated specimen exhibits rapid weightlessness. After the oxidation for $25 \mathrm{~h}$, the curve showed a rising trend. The generation of $\mathrm{CO}_{2}$ and $\mathrm{CO}$ results from the formation of the holes and bubbles in the generated glass layer [37]. As the oxidation time goes on, these micro-cracks sealed quickly at $1773 \mathrm{~K}$ with the expansion of $\mathrm{Si}$ and $\mathrm{SiC}$ phases in the coating [36] and the bridge of the SiCNWs and CNTs. A large number of the 
gases $\left(\mathrm{CO}, \mathrm{CO}_{2}\right)$ would be accumulated at the interface between the glass layer and the coating, which would then exert certain pressure for the glass layer, leading to the generation of the bubbles in the glass layer (Fig. 8(i)). Once the pressure of these gases exceed the surface tension of the bubbles, these gases would get out through the glass layer due to the low viscosity of glass layer at $1773 \mathrm{~K}$, left the holes within the glass layer (Fig. 8(j)). It can be concluded that the isothermal oxidation protective ability of the coating can be significantly increased by introducing SiCNWs and CNTs.

Detailed explanations are given based on SEM investigations for the as-deposited coatings after oxidation. Fig. 9(a) exhibits the surface SEM image of the SiC coated C/Cs without SiCNWs and CNTs after oxidation at $1773 \mathrm{~K}$ for $45 \mathrm{~h}$. Fig. 9(b) is the SEM image of the SiC coating toughed by SiCNWs and CNTs after oxidation for $100 \mathrm{~h}$. For the specimen without SiCNWs and CNTs, there are abundant pits and cracks on the surface of the SiC coatings (Fig. 9(a)). It is resulted from the evaporation of gaseous and mismatch of CTE between coating and C/C substrate, respectively. Whereas for the specimen containing SiCNWs and CNTs, these defects are significantly decreased (Fig. 9(b)). As shown in Fig. 9(b), the micro-crack first extended toward coating, and then it does not go straight through the holes, bubbles or the continuous glass layer, but deflects and finally comes to an end. Compared with the specimens without SiCNWs and CNTs, the cracks within the reinforced coating were discontinuously, which can not extend straightly from the beginning to the end, but deflect to a certain degree. Besides, the "crack termination" can be observed from 
part A in Fig. 9(b). It also can be seen that a continuous $\mathrm{SiO}_{2}$ glass layer formed on the coating due to its oxidation. As a result, the existence of SiCNWs and CNTs contribute to the deflection or the termination of micro-cracks. There is no big-scale micro-cracks in the coating, and these micro-cracks are small in width and length. These appearances indicate that the generated micro-cracks are due to the volume change of $\mathrm{SiO}_{2}$ glass during the cooling process [38].

The co-deposited SiCNWs and CNTs could decrease the oxygen diffusion and control the flow of melted $\mathrm{SiO}_{2}$ to form a continuous glass layer. The co-deposited SiCNWs and CNTs was used as the reinforcement composites to elevate the toughness of the coating and decrease the size of cracks, which could contribute to protect the $\mathrm{C} / \mathrm{Cs}$ with their own properties. The continuous glass layer indicates that self-heal rate is faster than SiC coating containing without SiCNWs and CNTs.

Moreover, obvious differences are also observed from the SiC coating with and without SiCNWs and CNTs after oxidation at $1773 \mathrm{~K}$ (as shown in Table 1). The amount of the holes and pits in the neat $\mathrm{SiC}$ coating is $25-33 / \mathrm{mm}^{2}$ and only $5-10 / \mathrm{mm}^{2}$ for the SiC coating with SiCNWs and CNTs. The diameters of the holes among them are $16-52 \mu \mathrm{m}$ and $25-33 \mu \mathrm{m}$, respectively. The size of the microcracks of the SiC coating without SiCNWs and CNTs is 5-10 $\mu \mathrm{m}$ and 0.8-1.5 $\mu \mathrm{m}$ for latter one. The differences among the micro-cracks, holes and pits may come from the introduction of the co-deposition of SiCNWs and CNTs. Oxygen can penetrate into the C/C matrix through these micro-cracks, and then bring about the oxidation of C/Cs. The micro-crack within $\mathrm{SiC}$ coating without $\mathrm{SiCNW}$ and CNTs is much larger, the 
coating need longer time to self-sealing than the oxygen penetrate into $\mathrm{C} / \mathrm{C}$ substrate through the through-thickness, $\mathrm{C} / \mathrm{Cs}$ would be oxidized during this process. With the toughening effect of $\mathrm{SiCNWs}$ and $\mathrm{CNTs}$, the formation of $\mathrm{SiO}_{2}$ is quicker than that of the oxygen penetrates into $\mathrm{C} / \mathrm{C}$ substrate through the through-thickness, the micro-cracks of small size will be decreased or eliminated quickly. The difference of the quantity and the diameter of the holes and pits were attributed to the existence of SiCNWs and CNTs. Fig. 9(c) is a representative pullout feature of numerous SiCNWs within the micro-crack that prevents the micro-crack from widening. It can be clearly observed that the size of micro-crack decreases from $1.5 \pm 0.5 \mu \mathrm{m}$ to $0.8 \pm 0.5 \mu \mathrm{m}$. Owing to the existence of the SiCNWs and CNTs, the micro-crack becomes narrow. In addition, at the top of the $\mathrm{SiC}$ nanowire the diameter was smaller than the joint of framework, and which occurred large deformation. It implied that the nanowires contribute to reduce the size of micro-cracks. Therefore, it is reasonable to believe that the SiCNWs and CNTs contribute to the alleviation of the thermal stress and the decreasing of the occurrence of the pits and defects of the coating. The XRD pattern (Fig. 9(d)) demonstrates that the oxidized coating consists of $\mathrm{SiC}, \mathrm{SiO}_{2}$ and $\mathrm{Si}$ phases. To explore the toughening mechanism of the SiCNWs and CNTs, a series of experiments were carried out. For this purpose the specimens after oxidation were fractured by a hammer. The fracture of the SiC coated C/Cs with SiCNWs and CNTs after oxidation at $1773 \mathrm{~K}$ for $100 \mathrm{~h}$ were observed (Fig. 10). Fig. 10(a) displays the cross-section of $\mathrm{SiC}$ coating with the co-deposition of SiCNWs and CNTs after oxidation, from which plenty of drapes can be found near the fringe of the coating. 
Fig. 10(b) is the magnification of Fig. 10(a), from which lots of SiCNWs can be observed. They are located at the drapes or on the cross-section. The presence of the drapes was due to the existence of $\mathrm{SiCNW}$, indicating that the coating toughened by the bridging or pulling out. In addition, the rugged shape of the drapes on the cross section implies that the existence of SiCNWs can increase the adhesion of the coating when being oxidized. Fig. 10(c) shows the fracture of the coating after oxidation at $1773 \mathrm{~K}$. With the protection of the SiC coating, SiCNWs and CNTs were not oxidized completely. SiCNWs and CNTs were curled and deformed, which also confirmed that the existence of SiCNWs and CNTs, SiC coating can protect C/Cs from oxidation.

\section{Conclusion}

In this work, SiCNWs and CNTs film were co-deposited on C/Cs by EPD and then coated by $\mathrm{SiC}$ coating through reactive melt infiltration. The oxidation behavior at $1773 \mathrm{~K}$ in air has been investigated. The co-deposition of SiCNWs and CNTs film by EPD can modify the coating and reduce the micro-cracks to widening. The toughening mechanisms include the pullout, bridging and micro-crack deflection of SiCNWs and CNTs are studied. The different shapes of SiCNWs and CNTs are beneficial to the adhesion between $\mathrm{C} / \mathrm{Cs}$ and $\mathrm{SiC}$ coating. The existence of SiCNWs and CNTs can contribute to form a continuous $\mathrm{SiO}_{2}$ glass layer to provide a better anti-oxidation ability.

\section{Acknowledgment}

This work has been supported by the Innovation Foundation of Shanghai Aerospace Science and Technology (SAST 201470), the National Science Foundation 
of China under Grant No. 51502242 and the Research Fund of State Key Laboratory of Solidification Processing (NWPU), China (Grant No. 85-TZ-2013).

\section{Reference}

[1] C.A.A. Cairo, M.L.A. Gra A, C.R.M. Silva, J.C. Bressiani, Functionally gradient ceramic coating for carbon-carbon antioxidation protection, J. Eur. Ceram. Soc. $21(2001) 325-329$.

[2] N.S. Jacobson, D.M. Curry, Oxidation microstructure studies of reinforced carbon/carbon, Carbon 44 (2006) 1142-1150.

[3] C. Blanco, E. Casal, M. Granda, R. Menéndez, Influence of fibre-matrix interface on the fracture behavior of carbon-carbon composites, J. Eur. Ceram. Soc. 23 (2003) 2857-2866.

[4] T. Feng, H. Li, Q. Fu, X. Yang, H. Wu, High-temperature erosion resistance and aerodynamic oxidation mechanism of multi-layer $\mathrm{MoSi}_{2}-\mathrm{CrSi}_{2}-\mathrm{Si} / \mathrm{SiC}$ coated carbon/carbon composites in a wind tunnel at 1873K, Carbon 50 (2012) $2171-2178$.

[5] X. Ren, H. Li, Q. Fu, Y. Chu, K. Li, TaB $2-S i C-S i$ multiphase oxidation protective coating for SiC-coated carbon/carbon composites, J. Eur. Ceram. Soc. 33 (2013) 2953-2959.

[6] C. Verdon, O. Szwedek, A. Allemand, S. Jacques, Y. Le Petitcorps, P. David, High temperature oxidation of two- and three-dimensional hafnium carbide and silicon carbide coatings, J. Eur. Ceram. Soc. 34 (2014) 879-887.

[7] T. Feng, H. Li, Q. Fu, X. Shen, H. Wu, Microstructure and oxidation of multi-layer $\mathrm{MoSi}_{2}-\mathrm{CrSi}_{2}-\mathrm{Si}$ coatings for $\mathrm{SiC}$ coated carbon/carbon composites, Corros. Sci. 52 (2010) 3011-3017.

[8] Y. Zhang, J. Ren, S. Tian, H. Li, Z. Hu. SiC coating toughened by HfC nanowires 
to protect C/C composites against oxidation, Appl. Surf. Sci. 311 (2014) $208-213$.

[9] T. Feng, H. Li, Q. Fu, H. Wu, X. Shen, Influence of $\mathrm{Cr}$ content on the microstructure and anti-oxidation property of $\mathrm{MoSi}_{2}-\mathrm{CrSi}_{2}-\mathrm{Si}$ multi-composition coating for SiC coated carbon/carbon composites, J. Alloy Compd. 501 (2010) $20-24$.

[10] G. Zheng, H. Mizuki, H. Sano, Y. Uchiyama, CNT-PyC-SiC/SiC double-layer oxidation-protection coating on C/C composite, Carbon 46 (2008) 1808-1811.

[11] Q. Fu, H. Li, Z. Zhang, X. Zeng, K. Li , SiC nanowire-toughened $\mathrm{MoSi}_{2}-\mathrm{SiC}$ coating to protect carbon/carbon composites against oxidation, Corros. Sci. 52 (2010) 1879-1882.

[12] J. Huang, X. Zeng, H. Li, X. Xiong, Y. Fu, Influence of the preparation temperature on the phase, microstructure and anti-oxidation property of a SiC coating for C/C composites, Carbon 42 (2004) 1517-1521.

[13] L. Cao, Z. Bai, J. Huang, H. OuYang, C. Li, Fabrication of gradient C/CSiC-MoSi2 composites with enhanced ablation performance, Ceram.Int. 42 (2016) 12289-12296.

[14] Y. Li, L. Guo, Q. Song, H. Li, Q. Fu, K. Li, Oxidation pre-treatment and electrophoretic deposition of $\mathrm{SiC}$ nanowires to improve the thermal shock resistance of $\mathrm{SiC}$ coating for $\mathrm{C} / \mathrm{C}$ composites, J. Alloy Compd. 636 (2015) 165-170.

[15] Y. Zhang, H. Li, Z. Hu, J. Ren, K. Li, Microstructure and oxidation resistance of Si-Mo-B coating for C/SiC coated carbon/carbon composites, Corros. Sci. 72 (2012) 150-155.

[16] H. Li, Y. Zhang, Q. Fu, K. Li, J. Wei, D. Hou, Oxidation behavior of SiC 
nanoparticle-SiC oxidation protective coating for carbon/carbon composites at 1773 K, Carbon 45 (2007) 2704-2707.

[17] H. Li, Q. Fu, X. Shi, K. Li, Z. Hu, SiC whisker-toughened SiC oxidation protective coating for carbon/carbon composites, Carbon 44 (2006) 602-605.

[18] Q. Fu, H. Li, K. Li, X. Shi, Z. Hu, M. Huang, SiC whisker-toughened $\mathrm{MoSi}_{2}-\mathrm{SiC}-\mathrm{Si}$ coating to protect carbon/carbon composites against oxidation, Carbon 44 (2006) 1866-1869.

[19] Y. Chu, H. Li, Q. Fu, X. Shi, L. Qi, B. Wei, Oxidation-protective and mechanical properties of $\mathrm{SiC}$ nanowire-toughened $\mathrm{Si}-\mathrm{Mo}-\mathrm{Cr}$ composite coating for C/C composites, Corros. Sci. 58 (2012) 315-320.

[20] H. Li, X. Yang, Y. Chu, L. Li, Q. Fu, L. Qi, Oxidation protection of C/C composites with in situ bamboo-shaped $\mathrm{SiC}$ nanowire-toughened $\mathrm{Si}-\mathrm{Cr}$ coating, Corros. Sci. 74 (2013) 419-423.

[21] X. Qiang, H. Li, Y. Zhang, D. Yao, L. Guo, J. Wei, Fabrication and thermal shock resistance of in situ $\mathrm{SiC}$ nanowire- $\mathrm{SiC} / \mathrm{SiC}$ coating for carbon/carbon composites, Corros. Sci. 59 (2012) 343-347.

[22] J. Huang, L. Zhou, L.Cao, H. OuYang, W. Hao, C. Li, Effect of the incorporation of $\mathrm{SiC}$ nanowire on mullite/SiC protective coating for carbon/carbon composites, Corros. Sci. 107 (2016) 85-95.

[23] J. Huang, M. Liu, B. Wang, L. Cao, C. Xia, J. Wu, SiCn/SiC oxidation protective coating for carbon/carbon composites, Carbon 47 (2009) 1198-1201.

[24] Y. Zhang, J. Ren, S. Tian, H. Li, Z. Hu, SiC coating toughened by HfC nanowires to protect $\mathrm{C} / \mathrm{C}$ composites against oxidation, Appl. Surf. Sci. 311 (2014) 208-213.

[25] A. Simon, M. Seyring, S. Kämnitz, H. Richter, I. Voigt, M. Rettenmayr, U. 
Ritter, Carbon nanotubes and carbon nanofibers fabricated on tubular porous $\mathrm{Al}_{2} \mathrm{O}_{3}$ substrates, Carbon 90 (2015) 25-33.

[26] L. Feng, K. Li, Z. Si, H. Li, Q. Song, Y. Shan, S. Wen, Microstructure and thermal shock resistance of SiC/CNT-SiC double-layer coating for carbon/carbon composites, Ceram. Int. 40 (2014) 13683-13689.

[27] S. Wen, K. Li, Q. Song, Y. Shan, Y. Li, H. Li, H. Ma, Enhancement of the oxidation resistance of $\mathrm{C} / \mathrm{C}$ composites by depositing $\mathrm{SiC}$ nanowires onto carbon fibers by electrophoretic deposition, J. Alloy. Compd. 618 (2015) 336-342.

[28] L. BESRA, M. LIU. A review on fundamentals and applications of electrophoretic deposition (EPD), Prog. Mater. Sci. 52 (2007) 1-61.

[29] A.R. Boccaccini, J. Cho, T. Subhani, C. Kaya, F. Kaya, Electrophoretic deposition of carbon nanotube-ceramic nanocomposites, J. Eur. Ceram. Soc. 30 (2010) 1115-1129.

[30] Y. Li, L. Guo, Q. Song, L. Li, J. Lu, K. Li, S. Zhang, H. Li, Simultaneous improvements in flexural strength and ductility of carbon nanotube-doped carbon/carbon composites by depositing a pyrocarbon layer on carbon fibers, Ceram. int. 41 (2015) 1943-1949.

[31] J. Sun, Q. Fu, L. Guo, Y. Liu, C. Huo, H. Li. Effect of filler on the oxidation protective ability of $\mathrm{MoSi}_{2}$ coating for Mo substrate by halide activated pack cementation. Mater. Design 92 (2016) 602-609.

[32] Nakashima S, Harima H. Raman Investigation of SiC Polytypes. Phys. Stat. Sol. 162 (1997) 5.

[33] H. Qian, A. Bismarck, E.S. Greenhalgh, M.S.P. Shaffer, Synthesis and 
characterization of carbon nanotubes grown on silica fibres by injection CVD, Carbon 48 (2010) 277-286.

[34] Zeng XR, Li HJ, Yang Z. Effect of microstructure and component of MoSi2-SiC multilayer ceramic coating on oxidation resistance. J. Chin. Ceram. Soc. 1999;27(1):8 - 14 .

[35] Hinze JW, Graham HC. The active oxidation of $\mathrm{Si}$ and $\mathrm{SiC}$ in the viscous gas-flow regime. J. Electrochem Soc. 1976;123(7):1066 - 73.

[36] Y. Chu, H. Li, Q. Fu, H. Wang, X. Hou, X. Zou, G. Shang, Oxidation protection of $\mathrm{C} / \mathrm{C}$ composites with a multilayer coating of $\mathrm{SiC}$ and $\mathrm{Si}+\mathrm{SiC}+\mathrm{SiC}$ nanowires, Carbon 50(2012) 1280-1288.

[37] Y. Chu, H. Li, Q. Fu, L. Qi, X. Zou, Toughening by SiC Nanowires in a Dense SiC-Si Ceramic Coating for Oxidation Protection of C/C Composites, J. Eur. Ceram. Soc. 95(2012) 3691-3697.

[38] Y. Chu, H. Li, Q. Fu, L. Qi, L. Li, Y. Liu, Oxidation protection and behavior of $\mathrm{C} / \mathrm{C}$ composites with an in situ $\mathrm{SiC}$ nanowire-SiC-Si/SiC-Si coating, Corros. Sci. 70(2013) 285-289. 


\section{Figure captions}

Figure 1 Schematic diagram of the SiCNWs and CNTs hybrid reinforcement toughed SiC coating.

Figure 2 Schematic diagram of the co-deposition of SiCNWs and CNTs on $\mathrm{C} / \mathrm{C}$ composites in EPD cell.

Figure 3 Raman spectra of the co-deposition of SiCNWs and CNTs (curve (a)) and C/C specimens (curve (b)).

Figure 4 SEM images of the specimen after the co-deposition of SiCNWs and CNTs by EPD for 120 s: (a) Cross section image; (b) Surface image; (c) Magnification of (b).

Figure 5 (a) Magnification of CNTs in (b); (b) TEM image of the co-deposition of SiCNWs and CNTs; (c) Magnification of SiCNWs in (b).

Figure $6 \mathrm{SiC}$ coating without (a) and with (b) SiCNWs and CNTs; (c) XRD pattern of the SiCNWs/CNTs-reinforced coating; (d and e) High magnification of SiC coating containing SiCNWs and CNTs; (f) Bridging effect of the SiC coating toughed by SiCNWs and CNTs.

Figure 7 Variation in weight losses percentage of the $\mathrm{SiC}$ coated $\mathrm{C} / \mathrm{Cs}$ during exposed to the atmosphere.

Figure 8 Schematic illustration of the isothermal oxidation process of the coating: (a)-(d) SiC coating; (e)-(h) SiCNWs/CNTs-toughened SiC coating.

Figure 9 SEM images of the $\mathrm{SiC}$ coated $\mathrm{C} / \mathrm{Cs}$ after oxidation without (a) and with (b) the co-deposition of SiCNWs and CNTs; (c) Magnification of (b); (d) XRD pattern of 
the coated specimens after oxidation tests.

Figure 10 (a) Cross section of $\mathrm{SiC}$ coating with the co-deposition of SiCNWs and CNTs after oxidation; (b) Magnification of (a); (c) Fracture of the coating after oxidation at $1773 \mathrm{~K}$. 


\section{FIGURES}

Figure 1
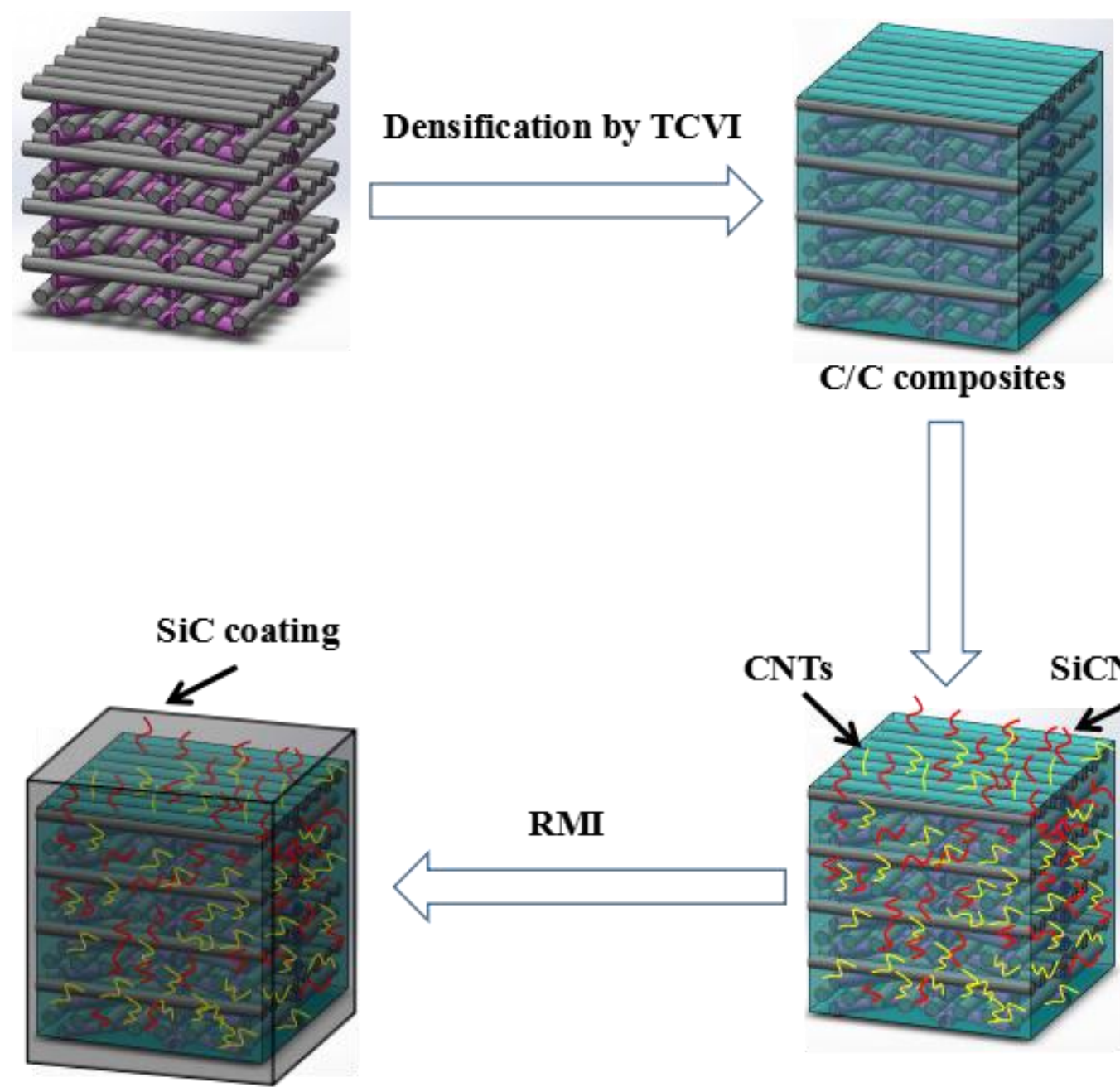
Figure 2

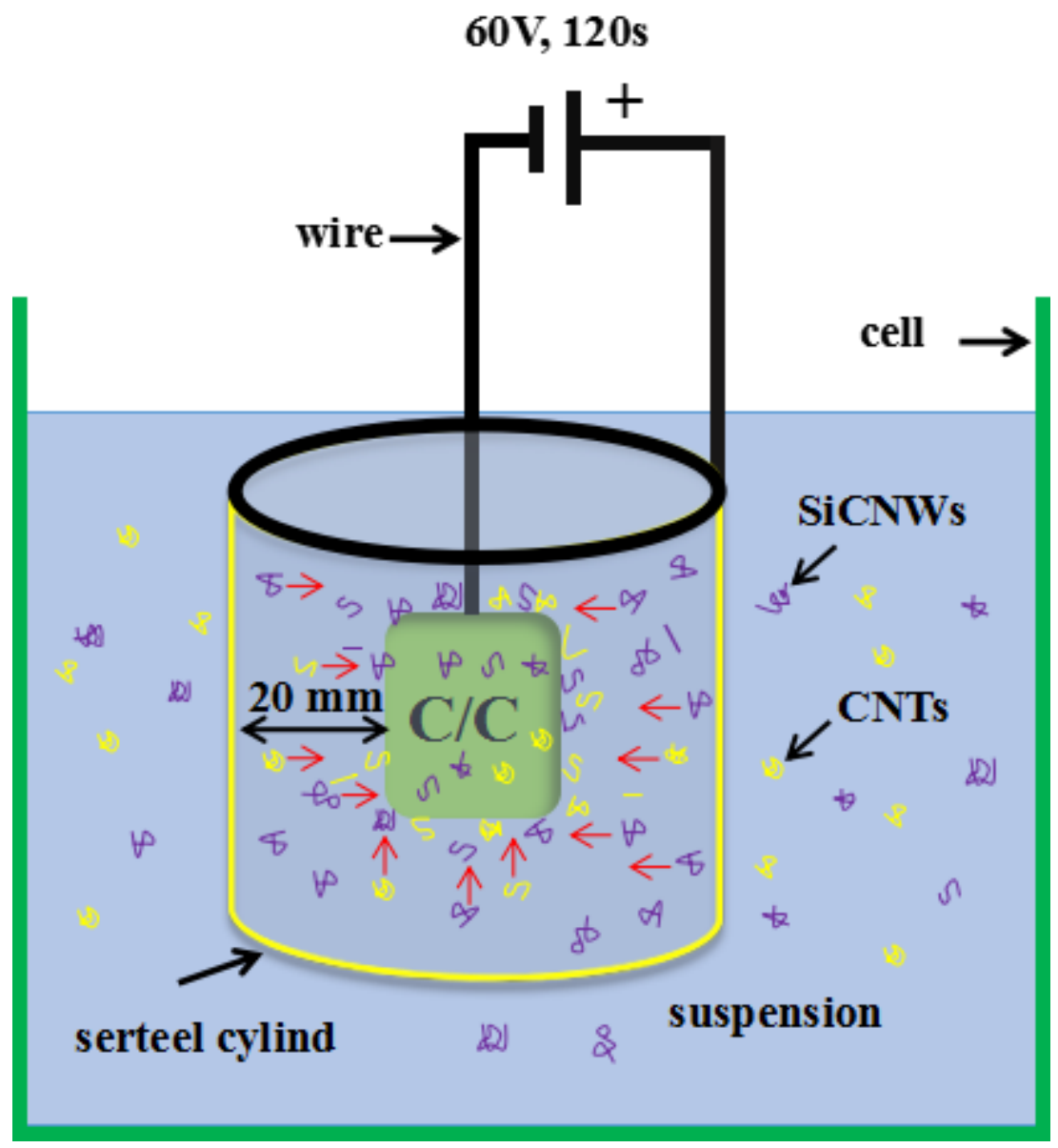


Figure 3

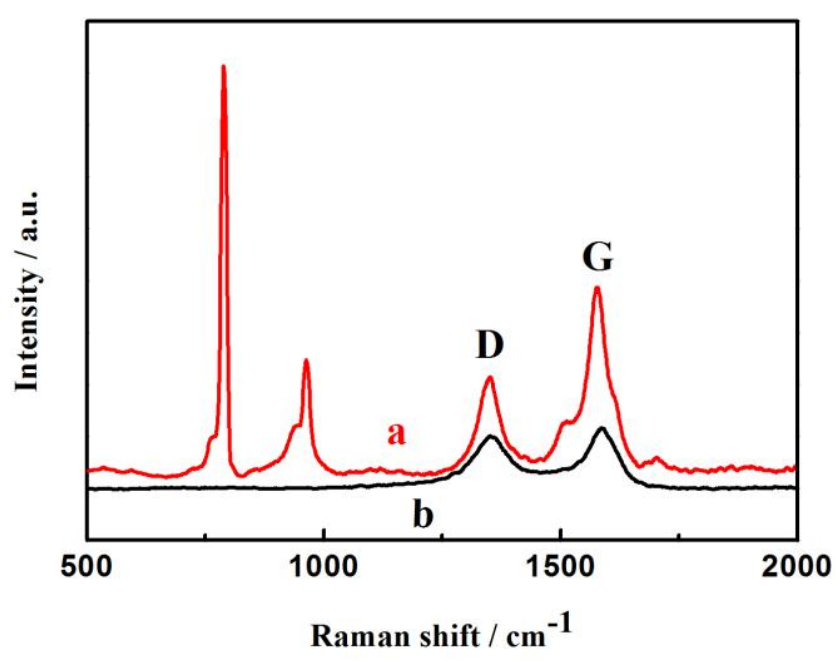


Figure 4
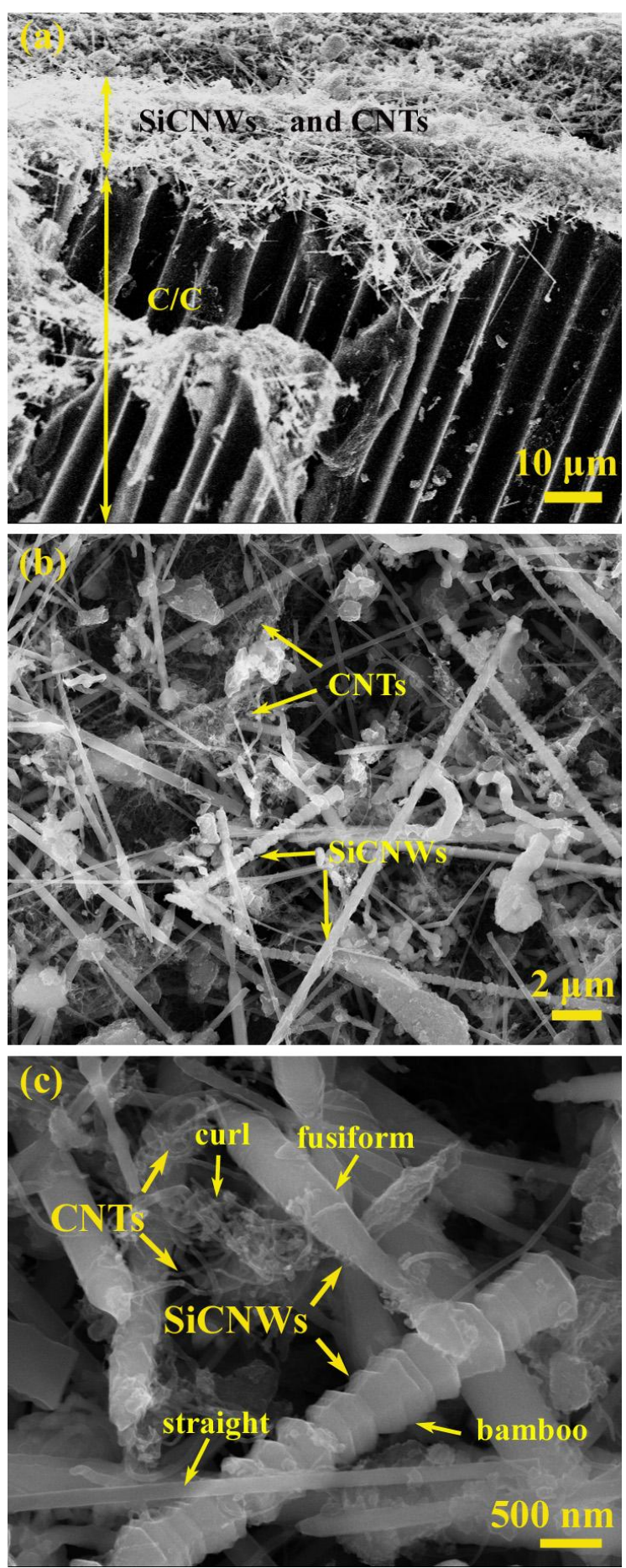
Figure 5

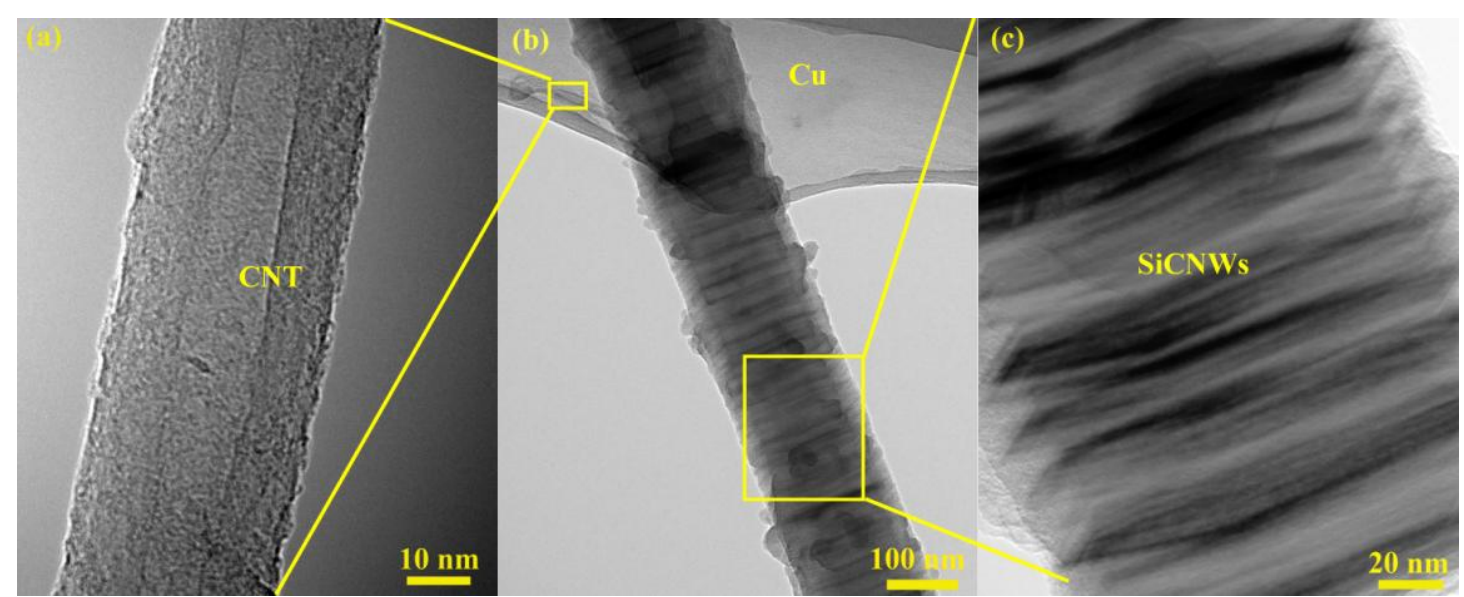


Figure 6
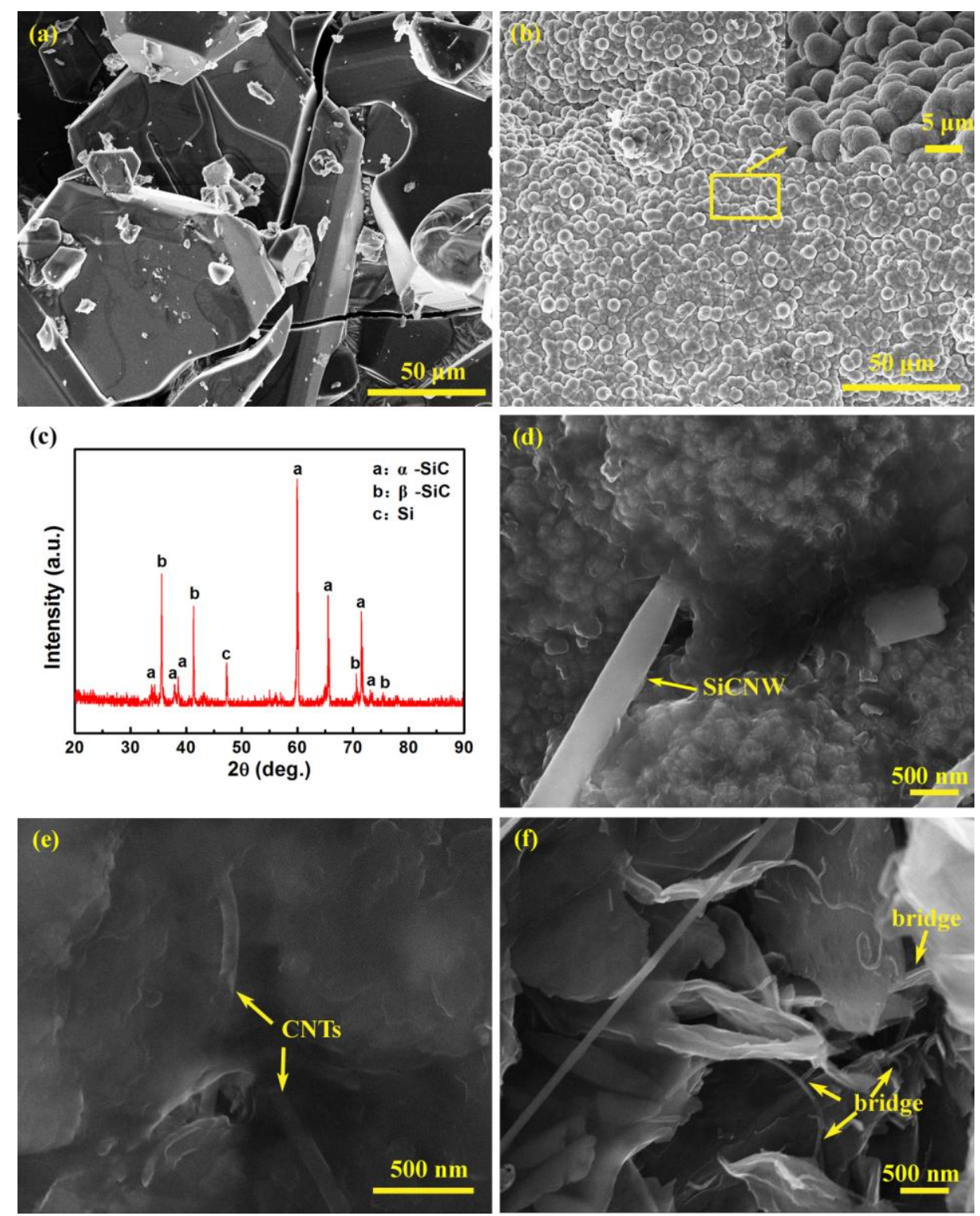
Figure 7

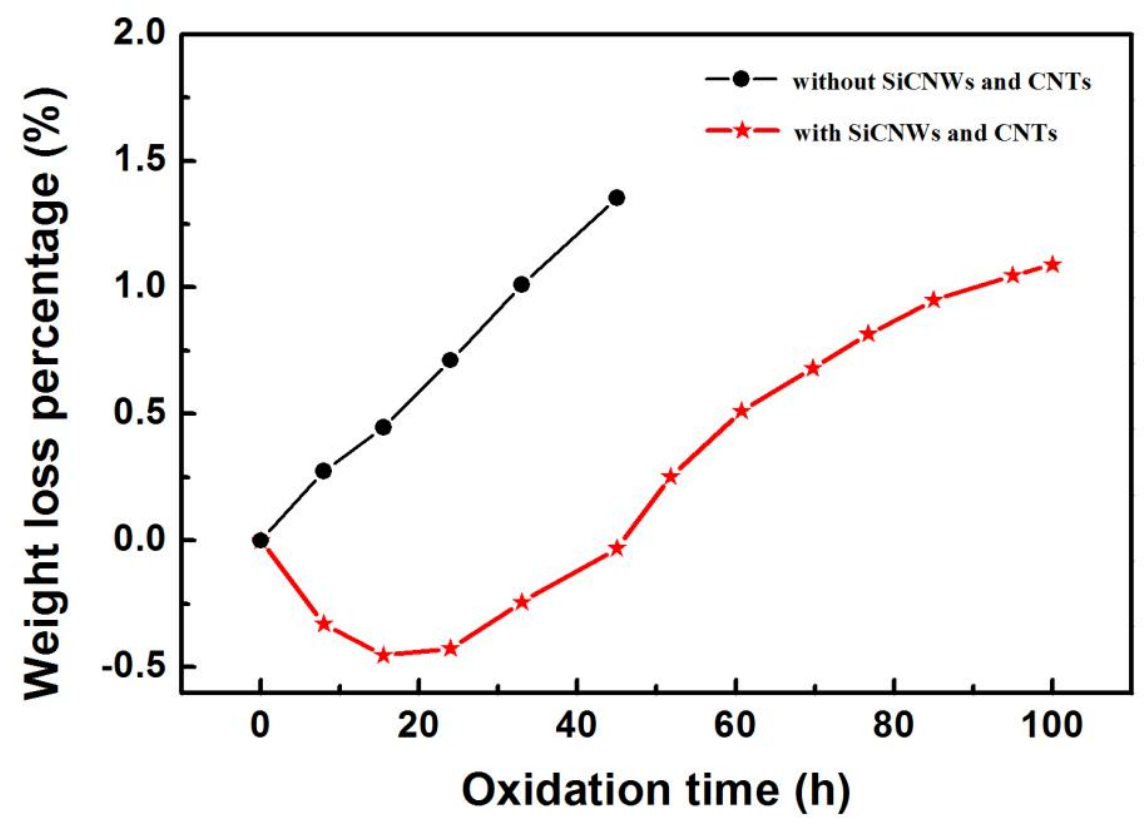


Figure 8

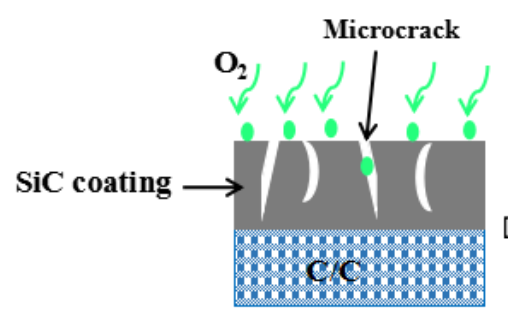

(a)

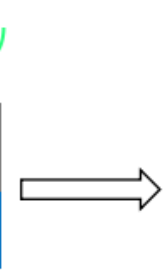

\% -

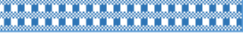

(b)

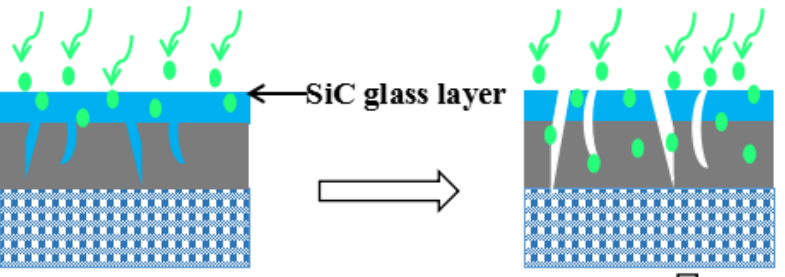

(c)

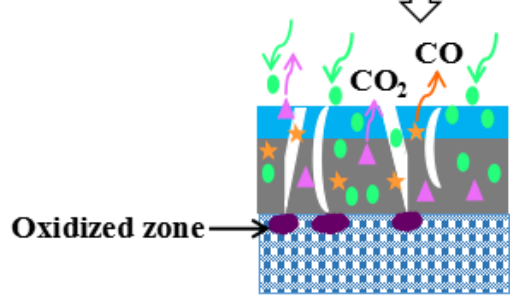

(d)

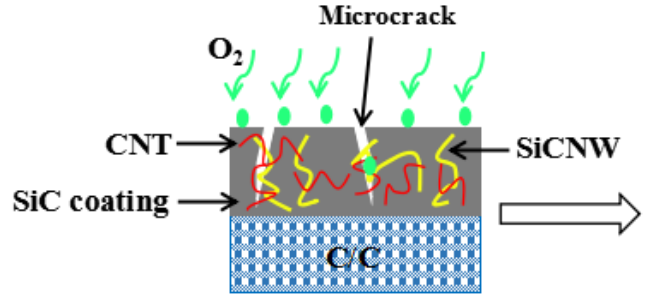

(e)

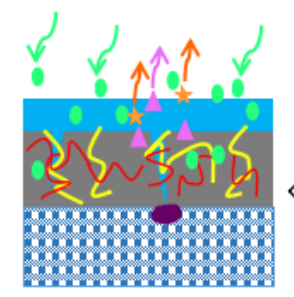

(j)

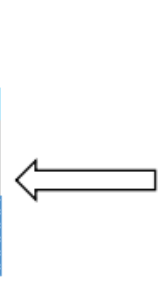

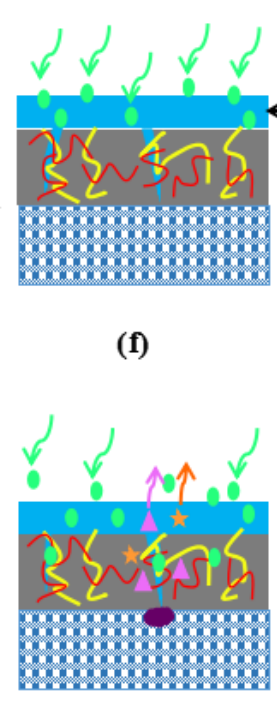

(i)

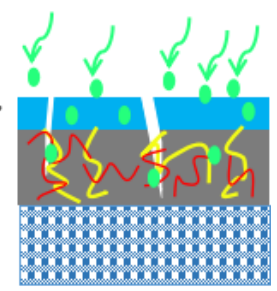

(g)

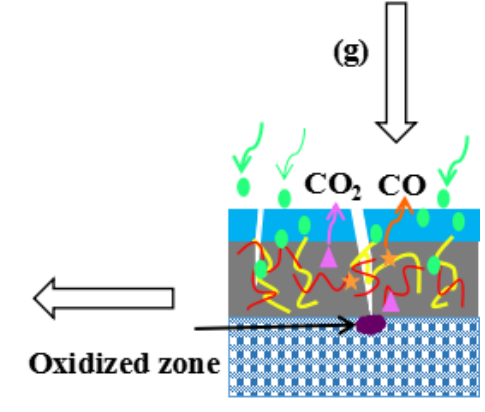

(h) 
Figure 9
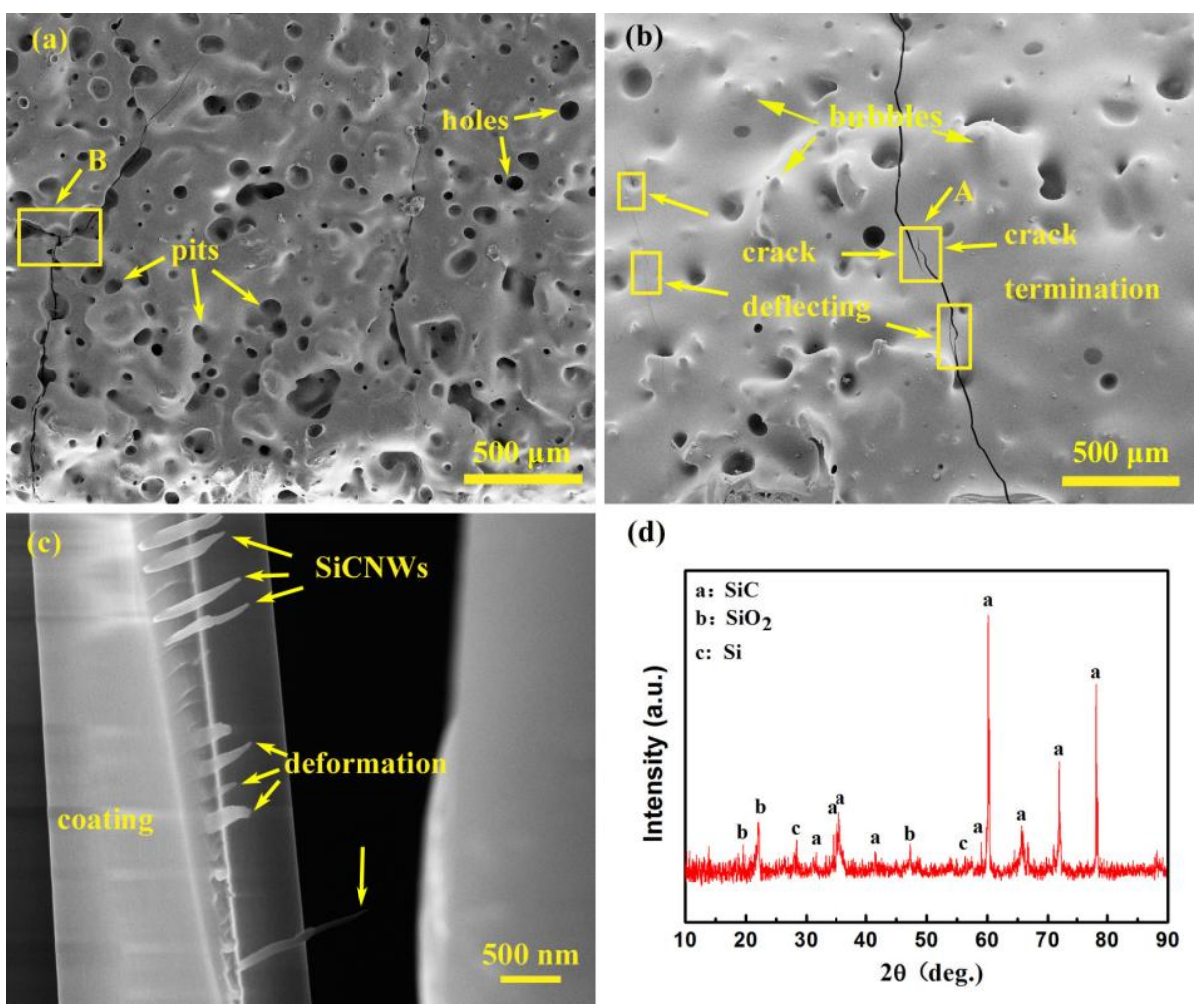

(d)

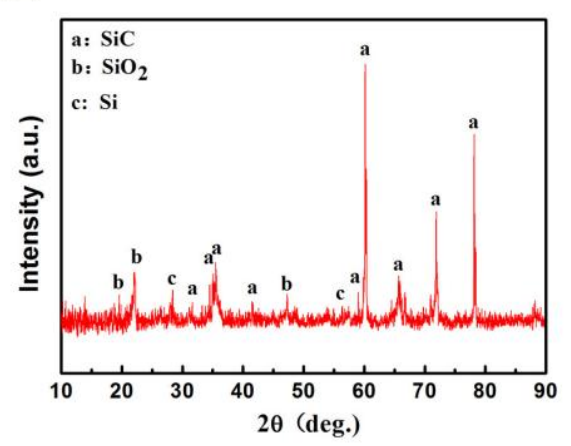


Figure 10
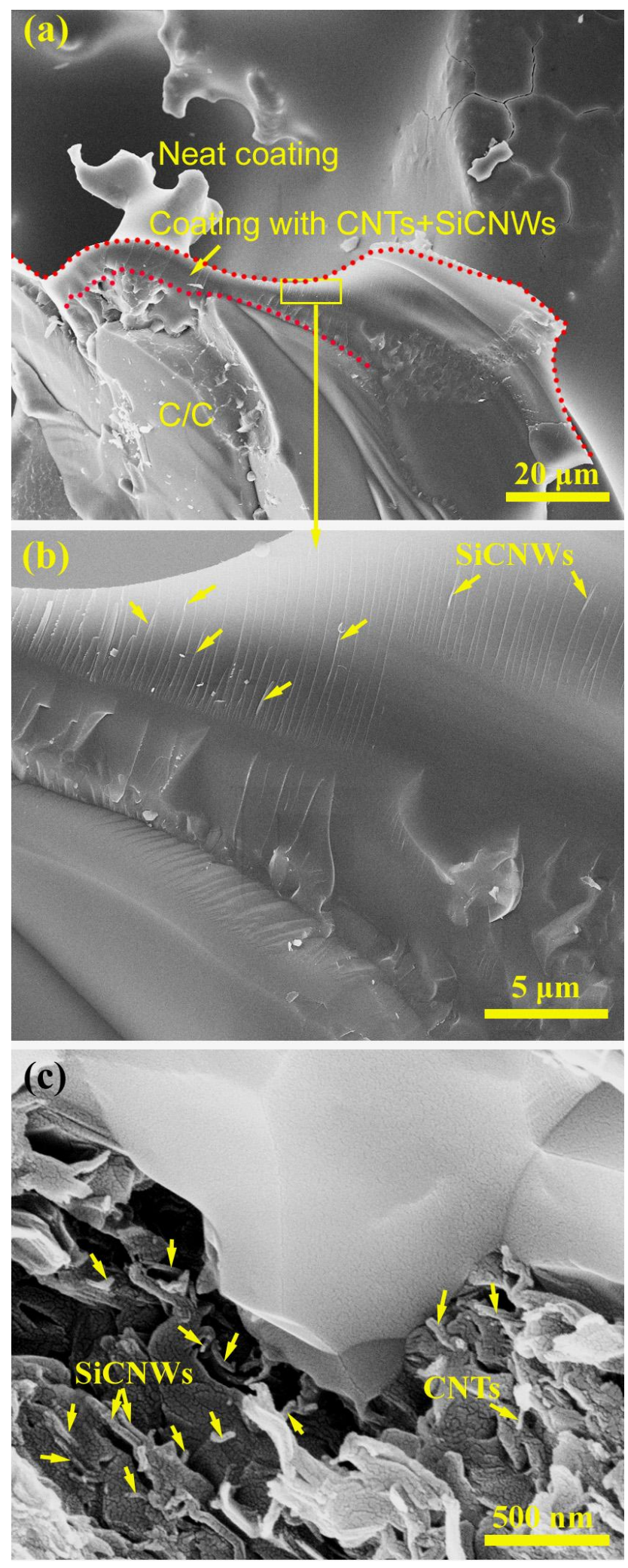
Table $1 \mathrm{SiC}$ coating contain without and with the co-deposition of SiCNWs and CNTs after oxidation at $1773 K$.

\begin{tabular}{ccccc}
\hline specimens & $\begin{array}{c}\text { Oxidation } \\
\text { time }(\mathrm{h})\end{array}$ & $\begin{array}{c}\text { Holes and } \\
\text { pits }\left(\mathrm{mm}^{-2}\right)\end{array}$ & $\begin{array}{c}\text { Diameter of } \\
\text { holes }(\mu \mathrm{m})\end{array}$ & $\begin{array}{c}\text { Size of } \\
\text { micro-cracks } \\
(\mu \mathrm{m})\end{array}$ \\
\hline $\begin{array}{c}\text { Without } \\
\text { SiCNWs } \\
\text { and CNTs } \\
\begin{array}{c}\text { With } \\
\text { SiCNWs }\end{array}\end{array}$ & 45 & $23-28$ & $16-52$ & $5-10$ \\
and CNTs & 100 & $5-7$ & $25-33$ & $0.8-1.5$ \\
\hline
\end{tabular}

